\title{
High dose intravitreal ganciclovir for CMV retinitis: a shelf life and cost comparison study
}

\author{
N Morlet, S Young, D Naidoo, T Fong, M T Coroneo
}

\begin{abstract}
Background-It was previously found that high dose intravitreal ganciclovir provided superior treatment of cytomegalovirus retinitis compared with intravenous treatment. This study examined the stability and solubility of the ganciclovir solution to determine the shelf life of prepared solution, and compared the cost of intravitreal with intravenous therapy.
\end{abstract}

Methods-For the solubility studies high performance liquid chromatography was used to determine the ganciclovir concentration in various solutions. Measurements were taken of freshly made $20 \mathrm{mg} / \mathrm{ml}$ solution, the same solution stored at room temperature or frozen for 10,17 , and 24 days, after the solution was filtered, and after it was heated at $56^{\circ} \mathrm{C}$. For the cost comparison analysis the cost of 22 patients treated exclusively with intravitreal high dose ganciclovir was compared with cost estimates for the same patients treated with a standard intravenous therapy regimen over the same time.

Results-There was little variation in the concentration of ganciclovir regardless of the storage conditions, suggesting that the $20 \mathrm{mg} / \mathrm{ml}$ solution was very stable. The heating and filtering experiments suggest that maximum solubility was achieved both in the freshly prepared and thawed frozen stored solution. The total cost of the intravitreal treatment was Aus $\$ 172435$ and the estimate of intravenous treatment was Aus $\$ 490521$. This represents a total saving of $\$ 318086(65 \%)$, or $\$ 14458$ per patient. The average number of weeks of treatment for each patient was 27.9 (613 weeks/22 patients), so the saving per patient per year was $\$ 29946$.

Conclusion-High dose intravitreal ganciclovir therapy may be administered in a very cost effective way, which along with its acceptability, safety, and clinical efficacy make it an attractive method of treatment of $\mathrm{CMV}$ retinitis.

(Br f Ophthalmol 1995; 79: 753-755)

Ophthalmology

N Morlet

$S$ Young

M T Coroneo

Department of Clinical Chemistry

D Naidoo

Pharmacy Department T Fong

Correspondence to:

Dr N Morlet, Moorfields Eye Hospital, City Road, London EC1V 2PD.

Accepted for publication 24 April 1995

We prefer high dose $(2 \mathrm{mg} / 0 \cdot 1 \mathrm{ml})$ intravitreal ganciclovir for the treatment of cytomegalovirus (CMV) retinitis because we believe that it offers better control of the infection than intravenous therapy. ${ }^{1}$ In our most recent series of 22 patients (35 eyes) complete early resolution was achieved in all cases, with only two patients relapsing on maintenance, and a median time to relapse of 42 weeks. ${ }^{2}$ We have not experienced any toxicity problems with these patients which were attributable to this therapy, and complications from the injection procedure were infrequent. ${ }^{12}$

Apart from superior control of retinitis, this therapy offers advantages in terms of quality of life for the patient, and significant cost savings when compared with intravenous therapy.

This study examined the stability and solubility of the ganciclovir solution to determine the shelf life of the made up injections, and compared the cost of intravitreal with intravenous therapy.

\section{Methods}

STABILITY AND SOLUBILITY STUDIES

Ganciclovir was made up from $500 \mathrm{mg}$ ampoules as a $20 \mathrm{mg} / \mathrm{ml}$ solution $(2 \mathrm{mg} / 0.1 \mathrm{ml})$ in saline and stored at room temperature, $5^{\circ} \mathrm{C}$, and $-8^{\circ} \mathrm{C}$. After 10,17 , and 24 days' storage, the frozen samples were thawed at room temperature and the concentration of ganciclovir in the solution was measured by high performance liquid chromatography (HPLC). Those stored for 17 days were also heated in a water bath set at $56^{\circ} \mathrm{C}$ for 30 minutes and the ganciclovir concentration re-measured. The ganciclovir concentration in samples of freshly prepared solution was measured; then the concentration was re-measured after being filtered through a $22 \mu \mathrm{m}$ filter, or after being heated at $56^{\circ} \mathrm{C}$, and after being heated and filtered. For the HPLC analysis, equal volumes $(100 \mu \mathrm{l})$ of ganciclovir solution and $0.8 \mathrm{M}$ perchloric acid were mixed, vortexed, and centrifuged at $10000 \mathrm{~g}$ for 2 minutes. A $10 \mu \mathrm{l}$ aliquot of the supernatant was then injected into a $4.6 \mathrm{~mm}$ octadecyl silica column (Ultrasphere), using an ultraviolet detector set at $254 \mathrm{~nm}$ and a peak integrator. The elution buffer used was $20 \mathrm{mM}$ ammonia acetate and $1 \cdot 2 \%$ acetic acid at a flow rate of $1.5 \mathrm{ml} / \mathrm{min}$. The ganciclovir peak eluted at 9 minutes. Quantitation of ganciclovir concentrations was done by peak area comparison using a set of five prepared calibrators covering the measuring range. The $\mathrm{pH}$ of the $20 \mathrm{mg} / \mathrm{ml}$ solution used for the stability studies was also determined.

\section{COST COMPARISON ANALYSIS}

We treated 22 patients exclusively with high dose intravitreal ganciclovir over the period 1991-3. Although we planned to treat any symptomatic systemic disease with intravenous ganciclovir, none required this therapy. All patients were treated as outpatients, visiting twice a week for 3 weeks for induction therapy, then weekly for maintenance therapy. A total 
Table 1 The stability of $20 \mathrm{mg} / \mathrm{ml}$ ganciclovir in saline stored at various temperatures and times. The concentrations $(\mathrm{mg} / \mathrm{ml})$ were determined by high performance liquid chromatography after thawing at room temperature

\begin{tabular}{llll}
\hline Days of storage & Room temperature & $5^{\circ} \mathrm{C}$ & $-8^{\circ} \mathrm{C}$ \\
\hline 10 & 20.66 & $20 \cdot 41$ & $20 \cdot 85$ \\
17 & 20.34 & $20 \cdot 25$ & $20 \cdot 41$ \\
24 & 20.36 & $20 \cdot 24$ & 20.53
\end{tabular}

of 613 weeks of therapy was delivered based on the survival of these patients. The cost of therapy (Australian dollars) was calculated assuming the ganciclovir cost Aus $\$ 63.19$ per ampoule, the standard charge for an outpatient visit by the hospital and the Commonwealth Medical Benefits Schedule (MBS) fee for an intravitreal injection in a hospital. The pharmacy costs were a reasonable estimate of staff, depreciation, and disposable costs. Injections were made up monthly in sealed $1.0 \mathrm{ml}$ syringes in the laminar flow hood. One ampoule of ganciclovir was used on each occasion. The syringes were then kept frozen at $-8^{\circ} \mathrm{C}$ until used, or discarded after 1 month.

The potential cost of intravenous therapy for this group over the same period of time was estimated assuming all the patients received a standard induction of $500 \mathrm{mg}$ twice daily for 14 days in hospital, then maintenance therapy of $750 \mathrm{mg}$, three times a week at a day centre as an outpatient (using a total of five ampoules of ganciclovir per week). We assumed that all patients had a subcutaneous infusion port inserted for maintenance therapy, and that there were no complications or interruptions to therapy. The standard charge by the hospital for the hospital stay, theatre costs, and outpatient visits was used, and the MBS fee for the surgeon, anaesthetist, and fortnightly full blood count (FBC) cost was used. Again the pharmacy costs were a reasonable estimate of staff, depreciation, and disposable costs of preparing the infusions.

\section{Results}

The stability and solubility measurements are presented in Tables 1 and 2 . There was little variation in the concentration of ganciclovir regardless of the storage conditions, suggesting that the $20 \mathrm{mg} / \mathrm{ml}$ solution was very stable. The $\mathrm{pH}$ of the made up solution was 10.9 , which ensures optimum solubility in accordance with the manufacturer's specification. The heating and filtering experiments suggest that maximum solubility was achieved both in the freshly prepared solution, and in the thawed frozen

Table 2 The solubility of $20 \mathrm{mg} / \mathrm{ml}$ ganciclovir in saline measured by high performance liquid chromatography, freshly prepared and after storage at $-8^{\circ} \mathrm{C}$ for 17 days

\begin{tabular}{ll}
\hline Treatment & $\begin{array}{c}\text { Concentration } \\
(\mathrm{mg} / \mathrm{ml})\end{array}$ \\
\hline $\begin{array}{l}\text { Freshly prepared } \\
\text { Freshly prepared and filtered }\end{array}$ & 19.93 \\
$\begin{array}{l}\text { Freshly prepared and heated at } 56^{\circ} \mathrm{C} \text { for } 30 \\
\text { minutes }\end{array}$ & 20.21 \\
$\begin{array}{l}\text { Freshly prepared and filtered and heated } \\
\text { Stored at }-8^{\circ} \mathrm{C} \text { and thawed at room }\end{array}$ & $20 \cdot 18$ \\
temperature & $20 \cdot 21$ \\
$\begin{array}{l}\text { Stored at }-8^{\circ} \mathrm{C} \text { and heated at } 56^{\circ} \mathrm{C} \text { for } 30 \\
\text { minutes }\end{array}$ & 20.41 \\
\hline
\end{tabular}

solution. There were no problems with precipitation of ganciclovir during storage for up to 4 weeks. No by-products were seen on the HPLC spectrograph.

The cost comparison analysis is shown in Table 3. The total cost of the intravitreal treatment was $\$ 172435$ and the estimate of intravenous treatment was $\$ 490521$. This represents a total saving of $\$ 318086(65 \%)$, or $\$ 14458$ per patient. The average number of weeks of treatment for each patient was $27 \cdot 9$ (613 weeks/22 patients), so the saving per patient per year was $\$ 29946$.

\section{Discussion}

Ganciclovir is remarkably stable as a $20 \mathrm{mg} / \mathrm{ml}$ solution. We found that it can be made up as a batch of injections and stored safely for at least 1 month. This allows the efficient use of pharmacy services with little waste from each ampoule of ganciclovir. The eye clinic was also able to cater for newly diagnosed patients along with those attending for maintenance injections because the injections were made up in advance.

Not only did we find high dose intravitreal ganciclovir efficacious and safe, the patients found the therapy acceptable with minimal disruption of their day to day lives. The injections were well tolerated using our technique of topical anaesthesia and ocular decompression. ${ }^{34}$ For those who had experienced both treatments, most preferred the weekly intravitreal therapy compared with the need for at least thrice weekly intravenous treatment. Apart from the clinical and social benefits, a large saving in therapeutic expenditure was achieved using intravitreal therapy.

Endophthalmitis is potentially the most serious sight threatening complication of intravitreal injections. We experienced one case in our first series of patients, ${ }^{1}$ but none since using povidone-iodine preparation of the conjunctiva before injection. Retinal detachment and extensive vitreous haemorrhage are also potential sight threatening problems but we have not experienced these complications in over 2000 injections.

Table 3 Cost comparison analysis of 22 patients with cytomegalovirus retinitis treated exclusively with intravitreal ganciclovir (DHPG $2 \mathrm{mg} / 0.1 \mathrm{ml}$ ) and the estimated cost if those patients were treated with intravenous ganciclovir. (All costs in Australian dollars)

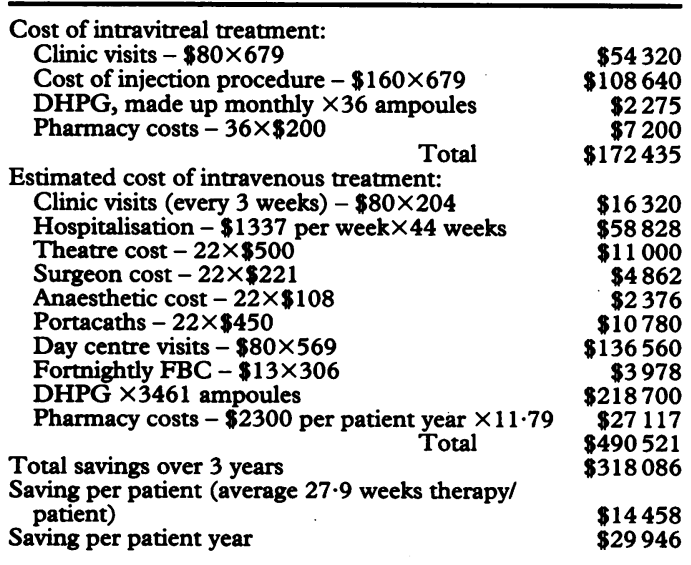


Some physicians may be concerned that the lack of systemic therapy will lead to a reduction in survival. ${ }^{56}$ We found that the median survival of our patients ( 30 weeks) was no shorter than the group of patients we previously treated with intravenous therapy. ${ }^{2}$ Although few of our patients receiving intravitreal therapy had systemic therapy, the decision to treat systemic disease with intravenous therapy was made by the attending physicians. Other studies using intravenous therapy found a similar median survival. ${ }^{7-9}$ The median survival for the ganciclovir treated group in the SOCA study was 34 weeks. ${ }^{9}$ Recently, Martin et al found that their group of patients treated exclusively with the intravitreal ganciclovir implant device survived 42 weeks. ${ }^{10} \mathrm{~A}$ controlled trial comparing the device with intravenous therapy is under way in the USA and will provide further data on the survival of each method of treatment.

There may also be concern that lack of systemic therapy would leave the unaffected contralateral eye at risk of infection. Although systemic therapy would be expected to offer better protection, there is little evidence to support this assumption. Contralateral disease developed in $15 \%$ on maintenance intravenous therapy in one study, ${ }^{11}$ and a large study of low dose intravitreal therapy found that contralateral disease developed in $11 \%$ of patients. ${ }^{12}$ However, $67 \%$ of contralateral eyes developed retinitis in the ganciclovir device study. ${ }^{10}$ Because of close monitoring of our patients, we were able to detect and treat disease in the second eye at a very early stage with little resultant visual loss.

Newer therapies under investigation may offer better treatment of CMV retinitis. Intravitreal (s)-1-(3-hydroxy-2-phosphonylmethoxypropyl) cytosine (HPMPC) is potentially very effective and convenient therapy, ${ }^{13}$ the implantable device ${ }^{10}$ is effective but expensive, oral treatment has yet to be demonstrated effective. However, ganciclovir solution is currently widely available and the techniques we have described are achievable by any ophthalmologist and hospital pharmacy.

High dose intravitreal ganciclovir therapy may be administered in a very cost effective way, which along with its acceptability to patients, safety, and clinical efficacy make it an attractive method of treatment of $\mathrm{CMV}$ retinitis.

The authors have no proprietary interest in the materials or methods described in this article.

1 Young SH, Morlet N, Heery S, Hollows FC, Coroneo MT High dose intravitreal ganciclovir in the treatment of High dose intravitreal ganciclovir in the treatment of
cytomegalovirus retinitis. Med $\mathcal{F}$ Aust 1992; 157: 370-3.

2 Young SH, Morlet N, Besen G, Wiley CA, Freeman WR, Jones $P$, et al. Improved treatment of cytomegalovirus retinitis in acquired immune deficiency syndrome with high-dose intravitreal ganciclovir. (in press).

3 Morlet N, Young SH, Strachan D, Coroneo MT Technique of intravitreal injection. Aust NZ F Ophthalmo 1993; 21: 130-1.

4 Morlet N, Young SH. Reduction of pressure rise due to intravitreal injection. Br $₹$ Ophthalmol 1993; 77: 572-3.

5 Spaide RF. Ganciclovir intraocular device and patient survival [Letter]. Arch Ophthalmol 1994; 112: 19-20.

6 Geier SA, Sadri I, Bogner JR, Goebel FD. Ganciclovir intraocular device and patient survival [Letter]. Arch Ophthalmol 1994; 112: 20.

7 Jacobson MA, O'Donnell J, Porteous D, Brodie HR, Feigal $\mathrm{D}$, Mills J. Retinal and gastrointestinal disease due to cytomegalovirus in patients with the acquired immunodeficiency syndrome: prevalence, natural history, and response to ganciclovir. $Q \mathcal{F} M e d$ 1988; 103: 473.

8 Holland GN, Sidikaro Y, Kreiger AE, Hardy D, Sakamoto MJ, Frenkel LM, et al. Treatment of cytomegalovirus retinopathy with ganciclovir. Ophthalmology 1987; 94: 815 .

9 Studies of Ocular Complications of AIDS Research Group, in collaboration with the AIDS Clinical Trials Group. Mortality in patients with the acquired immunodeficiency syndrome treated with either foscarnet or ganciclovir for cytomegalovirus retinitis. $N$ Engl f $\mathrm{Med}$ 1992; 326: 213.

10 Martin DF, Parks DJ, Mellow SD, Ferris FL, Walton RC, Remahey NA, et al. Treatment of CMV retinitis with an intraocular sustained release ganciclovir implant. Arch Ophthalmol 1994; 112: 1531-9.

11 Gross JG, Bozzette SA, Matthews WC, Spector SA, Abramson IS, McCutchan JA, et al. Longitudinal study of cytomegalovirus retinitis in acquired immunodeficiency cytomegalovirus retinitis in acquired im
syndrome. Ophthalmology 1990; 97: 681.

12 Cochereau-Massin I, Lehoang P, Lautier-Frau M, Zazoun $\mathrm{L}$, Marcel P, Robinet M, et al. Efficacy and tolerance of intravitreal ganciclovir in cytomegalovirus retinitis in acquired immune deficiency syndrome. Ophthalmology 1991; 98: 1348 .

13 Kirsch LS, Arevalo JF, De Clercq E, Chavez de la Paz E, Munguia D, Freeman WR. Intravitreal HPMPC for the treatment of CMV retinitis in AIDS patients. Ophthalmology 1994; 101 (suppl): 76. 